\title{
Exploring the socio-economic determinants of educational inequalities in diarrhoea among under-five children in low- and middle-income countries: a Fairlie decomposition analysis
}

\author{
Adeniyi Francis Fagbamigbe ${ }^{1,2^{*}}$ (1), Olukemi Grace Adebola ${ }^{3}$, Natisha Dukhi ${ }^{4}$ (i), \\ Omon Stellamaris Fagbamigbe ${ }^{5,6}$ and Olalekan A. Uthman ${ }^{2,7}$ (D)
}

\begin{abstract}
Background: What explains the underlying causes of educational inequalities in diarrhoea among under-five children in low- and middle-income countries (LMIC) is poorly exploited, operationalized, studied and understood. This paper aims to assess the magnitude of educational-related inequalities in the development of diarrhoea and decompose risk factors that contribute to these inequalities among under-five children (U5C) in LMIC.

Methods: Secondary data of 796,150 U5C from 63,378 neighbourhoods in 57 LMIC was pooled from the Demographic and Health Surveys (DHS) conducted between 2010 and 2019. The main determinate variable in this decomposition study was mothers' literacy levels. Descriptive and inferential statistics comprising of bivariable analysis and binary logistic multivariable Fairlie decomposition techniques were employed at $p=0.05$.

Results: Of the 57 countries, we found a statistically significant pro-illiterate odds ratio in 6 countries, 14 showed pro-literate inequality while the remaining 37 countries had no statistically significant educational-related inequality. The countries with pro-illiterate inequalities are Burundi $(\mathrm{OR}=1.11$; $95 \% \mathrm{Cl}: 1.01-1.21)$, Cameroon $(\mathrm{OR}=1.84 ; 95 \% \mathrm{Cl}$ : 1.66-2.05), Egypt ( $\mathrm{OR}=1.26 ; 95 \% \mathrm{Cl}: 1.12-1.43)$, Ghana ( $\mathrm{OR}=1.24 ; 95 \% \mathrm{Cl}: 1.06-1.47)$, Nigeria $(\mathrm{OR}=1.80 ; 95 \% \mathrm{Cl}$ : 1.68-1.93), and Togo (OR $=1.21 ; 95 \% \mathrm{Cl}: 1.06-1.38)$. Although there are variations in factors that contribute to proilliterate inequality across the 6 countries, the overall largest contributors to the inequality are household wealth status, maternal age, neighbourhood SES, birth order, toilet type, birth interval and place of residence. The widest pro-illiterate risk difference (RD) was in Cameroon (118.44/1000) while the pro-literate risk difference was widest in Albania $(-61.90 / 1000)$.
\end{abstract}

\footnotetext{
* Correspondence: franstel74@yahoo.com

'Department of Epidemiology and Medical Statistics, Faculty of Public Health, College of Medicine, University of Ibadan, Ibadan, Nigeria

2Warwick Centre for Global Health, Division of Health Sciences, University of Warwick, Coventry, UK

Full list of author information is available at the end of the article
}

C C The Author(s). 2021 Open Access This article is licensed under a Creative Commons Attribution 4.0 International License, which permits use, sharing, adaptation, distribution and reproduction in any medium or format, as long as you give appropriate credit to the original author(s) and the source, provide a link to the Creative Commons licence, and indicate if changes were made. The images or other third party material in this article are included in the article's Creative Commons licence, unless indicated otherwise in a credit line to the material. If material is not included in the article's Creative Commons licence and your intended use is not permitted by statutory regulation or exceeds the permitted use, you will need to obtain permission directly from the copyright holder. To view a copy of this licence, visit http://creativecommons.org/licenses/by/4.0/. The Creative Commons Public Domain Dedication waiver (http://creativecommons.org/publicdomain/zero/1.0/) applies to the data made available in this article, unless otherwise stated in a credit line to the data. 
Conclusions: The study identified educational inequalities in the prevalence of diarrhoea in children with wide variations in magnitude and contributions of the risk factors to pro-illiterate inequalities. This suggests that diarrhoea prevention strategies is a must in the pro-illiterate inequality countries and should be extended to educated mothers as well, especially in the pro-educated countries. There is a need for further studies to examine the contributions of structural and compositional factors associated with pro-educated inequalities in the prevalence of diarrhoea among U5C in LMIC.

Keywords: Diarrhoea, Educational inequalities, Fairlie decomposition, Low and middle-income countries, Risk difference

\section{Background}

Diarrhoea, the passage of loose or liquid stools three or more times per day, remains a major health challenge especially among under-five children (U5C) [1] in the low- and middle-income countries (LMIC). In lowincome countries, children under five years, experience on average three episodes of diarrhoea every year and each episode deprive the child of the nutrition required for growth [2]. In 2016, UNICEF reported that about a quarter of the nearly 6 million children who do not live beyond the age of 5 dies from diarrhoea or pneumonia [3]. The UNICEF maintains that LMIC is home to $62 \%$ of the world's U5C population but account for more than $90 \%$ of the global diarrhoea death [4]. It has been delineated that the fate of U5C is determined by inequities especially with regards to the regions of the world in which they are born and diarrhoea is prevalent and concentrated within the poorest of the poor populations of the world [4]. The report also indicated that 70 million children die before reaching their fifth birthday and children in LMIC are ten times more likely to be affected than children in high-income countries. UNICEF and WHO declared diarrhoea as the second leading killer of U5C [1]. Acute diarrhoea diseases remain a leading cause of global morbidity and mortality particularly among young children in resource-limited countries with malnourished children at higher odds [2, 5]. Children continue to face widespread regional disparities in their chances of survival and sub-Saharan Africa remains the region with the highest under-five mortality rate in the world [6]. This is an alarming reminder of the exceptional vulnerabilities of children in developing countries.

There are environmental, social and economic risk factors of diarrhoea in LMIC as revealed from past studies. Prominent among these factors are illiteracy, gross inadequacy of safe drinking water, sanitation facilities, and good hygiene [1, 2, 7-9]. Other studies revealed that in sub-Saharan Africa, socioeconomic factors such as place of residence, mother's educational level, household wealth strongly impacted U5C mortality $[3,10,11]$. As opined by Budhathoki et al., cultural and societal values and income level are determinants for diarrhoea in U5C particularly in developing countries [12]. Among the social dimensions responsible for diarrhoea-related child mortality, maternal education has consistently remained significant, with children of less-educated mothers being considerably at higher risk $[8,9]$. Also, reiterated is the fact that maternal education, lack of availability of latrine, lack of maternal handwashing and rural area residence correlated with childhood diarrhoea significantly [13].

Replete in literature is the importance of mother's level of education in the development of diarrhoea in U5C. For instance, Workie et al. asserted that as a primary caregiver all over the world, mothers play a central role in the management and prevention of diarrhoea [14]. Bohra et al. affirmed that maternal education plays an important role in determining access to water and sanitation, and inequalities in child mortality arising due to differential access especially in low-and middleincome countries [15]. Woldu et al. averred that mother's education and household economic status were significantly associated with high mortality in U5C due to diarrhoea diseases [16], Budhathoki et al. reaffirmed that children whose mothers had secondary education or higher have lower odds of diarrhoea in comparison to children of mothers with lower educational attainment [12]. A recent study showed that children whose mothers have never attended primary school, who lives where faeces are exposed and in buildings with earthen floors were significantly associated with diarrhoea [17]. UNICEF had linked women's education level to a child's health and survival among the U5C [18]. Literature is satiated with factors that increase the susceptibility of U5C to diarrhoea especially in LMIC, with mother's educational level most emphasized. Nonetheless, what explains the underlying causes of educational inequalities in diarrhoea among under-five children in low- and middleincome countries (LMIC) is poorly exploited, operationalized, studied and understood.

Inequalities in maternal education are a critical condition for the development of diarrhoea in U5C which remains a persistent burden among the LMIC of the world. However, the factors responsible for such disparities such as having diarrhoea have not been well 
studied. There is a need to understand such factors to proffer workable solutions. An understanding of the factors responsible for maternal educational inequalities is a necessity if there will be any remarkable progress to forestall the burden of diarrhoea among U5C. Such an understanding would inform interventions for diarrhoea prevention. We aimed to conduct multi-country analyses with efforts to decompose the educational-related inequalities in the development of diarrhoea among U5C in LMIC and also identified the risk factors contributing to these inequalities. Strategies to prevent diarrhoea are recommended, many of which emphasize the need to explore individual-, household and neighbourhood-level and country-specific factors.

\section{Methods}

\section{Study design and data}

We pooled the Demographic and Health Surveys (DHS) data from 57 LMIC in this study using the most recent successive DHS conducted within the last ten years (2010-2019) which captured information on diarrhoea experience among U5C and available as of April 2020. The DHSs are cross-sectional and nationally representative population-based household survey conducted periodically across the LMIC. The DHS uses a multi-stage stratified sampling design based on the states/divisions/ regions, district and clusters peculiar to each country. In each of the countries, the households are the sampling units and are selected from the clusters which are the primary sampling units (PSU) $[19,20]$. The DHS computes sampling weights to account for unequal selection probabilities within each cluster as a result of unequal sample sizes of the clusters. The application of the sampling weights ensured that the survey findings fully represent the target populations. A similar set of protocols, standardized questionnaires, similar interviewer training, supervision, and implementation were used in all the countries. The full details of the sampling methodologies are available at dhsprogram.com. Amongst others, the DHS collects data on children health care including common diseases, treatments, and care for all U5C of the sampled women. In all, we extracted the data of 796, 150 U5C from 63,378 neighbourhoods in 57 LMIC across the globe.

\section{Dependent variable}

The outcome variable in this study is the recent experience of diarrhoea. Diarrhoea is defined as "passage of liquid stools three or more times a day" [21, 22] and "recent experience of diarrhoea" as having any of the symptoms of diarrhoea within two weeks before the date of the interview [23]. The mothers were asked if any of their U5C had diarrhoea within two weeks preceding the survey. The responses were binary: Yes or No.

\section{Main determinant variable}

The main determinate variable in this decomposition study is mothers' literacy levels: illiterate or literate. We used mothers' reported education as a proxy for literacy in this study. Literacy, a key skill and an important measure of a population's level of education, is the ability to both read and write a short, simple statement about one's own life [24]. We, therefore, categorized education as having no formal education (Illiterate) and educated (can read and write: have a minimum of completed primary education - Literate).

\section{Independent variables}

The independent variables consist of individual-level and neighbourhood-level factors.

\section{Individual-level factors}

The individual-level factors comprises children, mothers' and the households' characteristics. Childs' characteristics: sex (male versus female), age in years $(<12$ months and 12-59 months), weight at birth (average+, small and very small), birth interval (firstborn, $<36$ months and $>=$ 36 months) and birth order (1, 2, 3 and 4+). Mothers' characteristics: maternal age (15-24, 25-34, 35-49), marital status (never, currently and formerly married), employment status (working or not working). Households' characteristics: access to media (at least one of radio, television or newspaper), sources of drinking water (improved or unimproved), toilet type (improved or unimproved), cooking fuel (clean fuel or biomass), housing materials (improved or unimproved).

\section{Neighbourhood-level factors}

The clusters are the PSUs in the DHS sampling technique. Typically, people of the same cluster share similar contextual factors $[19,20]$. We used the word "neighbourhood" to describe the clustering of the children within the same geographical cluster and "neighbours" as the members of the same cluster. The PSUs were identified using the most recent census in the respective countries. In this study, we considered living in rural areas and neighbourhood socioeconomic status (SES) as community-level variables. We computed the neighbourhood SES using the principal component analysis method, comprising of the proportion of respondents within the same neighbourhood who are from poor households and are not currently employed.

\section{Statistical analyses}

Descriptive and inferential statistics comprising of bivariable analysis and binary logistic multivariable Fairlie decomposition techniques were used for this study. The Z-test for equality of prevalence of diarrhoea among the children of illiterate and literate 
mothers within each country and region was conducted and reported in Table 1 while chi-square test of association between the explanatory variables and the outcome variable among the two groups of children were reported in Table 2. The risk difference (RD) in having diarrhoea was measured between U5C from illiterate mothers and those from literate mothers. An RD $>0$ suggests that diarrhoea is more prevalent among children born to illiterate mothers (pro-illiterate inequality). Whereas, a negative RD (< 0 ) indicates that diarrhoea is prevalent among children born to literate mothers (pro-literate inequality). A meta-analysis of the prevalence of diarrhoea among both groups of children in each of the countries was carried out. We estimated the fixed effects as the weighted country-specific RD and the random effect as the overall RD irrespective of a child's country (Fig. 1). Charts were used to show the distributions of the RDs (Figs. 2 and 3). Test of heterogeneity to ascertain that the 57 countries were different with regards to the odds ratio of having diarrhoea among children from illiterate and literate mothers was carried out, and a test of homogeneity of ORs among the 6 countries (with a significant odds ratio of having diarrhoea) to determine if the odds of having diarrhoea in those countries are homogenous or not. The heterogeneity in meta-analysis, measured by $\mathrm{I}^{2}$, refers to the variation in study outcomes between locations or countries; where a low $\mathrm{I}^{2}$ is an indication of low variability among locations. Lastly, the adjusted binary logistic regression method was applied to the 6 pro-illiterate countries to carry out a Fairlie decomposition analysis (FDA) on factors associated with the inequality and results presented in Fig. 4.

\section{Decomposition analysis}

Multivariable decomposition was used to quantify the contributions of risk factors to the differences in the prediction of an outcome of interest between two distinct groups in multivariate models [25]. The outputs from such regression models of group differences are partitioned into two components attributable to; (i) compositional differences between the two groups (endowments or explained differences) and (ii) a second component which is attributable to differences in the effects of the characteristics (coefficients or unexplained differences) [25]. The Blinder-Oaxaca Decomposition Analysis (BODA) [26-28] for linear regression models is the most famous of the models but it is not so reliable for nonlinear models such as binary logistic regression $[25,29]$. Other methods include the multivariate decomposition [25] and the Fairlie methods [29-33]. The Fairlie decomposition method is an extension of the BODA purposively developed for non-linear regression models including the logit and probit models. It was first developed in 1999 [34], updated in 2007 [30] with more simplifications to address path dependence issues and the method of incorporating sample weights in the technique in 2017 [29]. The Fairlie method has been reported to have more reliable estimates of non-linear regression models especially for the logit and probit models $[29,30,33,34]$ and was used in this study.

The decomposition analysis was carried out by calculating the difference between the predicted probability for one group (say the group of children from illiterate mothers (Group I)) using the other group's (say the group of children from literate mothers (Group L)) regression coefficients and the predicted probability for group I using its regression coefficients [29]. The Fairlie decomposition technique is operationalized to constrain the predicted probability between 0 and 1 .

The standard BODA of the two groups in linear regression is the average value of the dependent variable, $Y$, can be expressed as:

$$
\mathrm{Y}^{-I L}=\overline{\mathrm{Y}}^{I}-\overline{\mathrm{Y}}^{L}=\overbrace{\left[\left(\overline{\mathrm{X}}^{I}-\overline{\mathrm{X}}^{L}\right) \hat{\beta}^{I}\right]}^{1^{s t}}+\overbrace{\left[\overline{\mathrm{X}}^{L}\left(\hat{\beta}^{I}-\hat{\beta}^{L}\right)\right]}^{2^{n d}}
$$

Where $\overline{\mathrm{Y}}^{J}$ is the average probability of the binary outcome variable with a particular group $J$. The $\overline{\mathrm{X}}^{J}$ is a row vector of the average values of the explanatory variables and $\hat{\beta}^{J}$ is a vector of coefficient estimates for a particular group $J$. The numerical details have been reported $[27,35]$. Fairlie et al. showed that the alternative decomposition in eq. (1) for a nonlinear equation $Y=F(X)$, where $F$ is the logistic cumulative distribution function, can be expressed as:

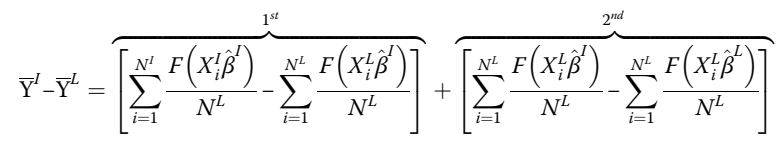

Where $N^{J}$ is the sample size for group $J$ [34]. Unlike in BODA where $F\left(X_{i} \beta\right)=X_{i} \beta$. $\overline{\mathrm{Y}}$ In eq. (2) is not necessarily the same as $F(\bar{X} \hat{\beta})$. In eqs. $(1,2)$, the 1 st term is the part of the gap in the binary outcome variable that is due to group differences in distributions of $X$, and the 2nd term is the part due to differences in the group processes determining levels of $Y$. The 2nd term also captures the portion of the binary outcome variable gap due to group differences in unmeasurable or unobserved endowments. The compliment of eq. (2) is also valid.

The estimation of the total contribution is the difference between the average values of the predicted probabilities. Using coefficient estimates from a logit regression model for a pooled sample, $\hat{\beta}^{*}$, the independ- 
Table 1 description of demographic and health surveys data by countries, educational and diarrhoea prevalence among under-five children in LMIC, 2010-2018

\begin{tabular}{|c|c|c|c|c|c|c|c|}
\hline \multirow[t]{2}{*}{ Country } & \multirow{2}{*}{$\begin{array}{l}\text { Year } \\
\text { of } \\
\text { Survey }\end{array}$} & \multirow{2}{*}{$\begin{array}{l}\text { Number } \\
\text { of } \\
\text { Clusters }\end{array}$} & \multirow{2}{*}{$\begin{array}{l}\text { Number of } \\
\text { Under } 5 \text { Children }\end{array}$} & \multirow{2}{*}{$\begin{array}{l}\text { Weighted } \\
\text { (\%) } \\
\text { Illiterate }\end{array}$} & \multicolumn{3}{|c|}{ Weighted Diarrhoea Prevalence (\%) } \\
\hline & & & & & Overall & allliterate & ${ }^{b}$ Literate \\
\hline All & & 63,378 & 796,150 & 33.5 & $* * 14.2$ & *15.8 & 13.4 \\
\hline Eastern Africa & & 6298 & 102,886 & 26.5 & 16.7 & *15.3 & 17.2 \\
\hline Burundi & 2016 & 554 & 12,431 & 46.8 & 22.5 & 22.9 & 22.2 \\
\hline Comoros & 2012 & 252 & 2949 & 46.6 & 17.0 & 16.9 & 17.0 \\
\hline Ethiopia & 2016 & 643 & 9916 & 65.9 & 11.9 & *11.3 & 13.1 \\
\hline Kenya & 2014 & 1593 & 19,889 & 11.9 & 15.4 & 14.2 & 15.5 \\
\hline Malawi & 2016 & 850 & 16,246 & 13.5 & 21.9 & *18.3 & 22.5 \\
\hline Mozambique & 2011 & 610 & 10,157 & 37.3 & 11.2 & 11.0 & 11.4 \\
\hline Rwanda & 2014 & 492 & 7474 & 14.7 & 12.2 & $* 14.0$ & 11.9 \\
\hline Tanzania & 2015 & 608 & 9445 & 21.3 & 12.1 & *9.4 & 12.8 \\
\hline Uganda & 2016 & 696 & 14,379 & 10.9 & 20.0 & 18.8 & 20.2 \\
\hline Middle Africa & & 3081 & 71,630 & 31.4 & 19.0 & 19.4 & 18.8 \\
\hline Angola & 2016 & 625 & 13,463 & 29.3 & 15.7 & *14.5 & 16.2 \\
\hline Cameroon & 2011 & 578 & 10,326 & 27.5 & 21.7 & *30.3 & 18.4 \\
\hline Chad & 2015 & 624 & 16,710 & 65.9 & 22.3 & *19.9 & 26.7 \\
\hline Congo & 2012 & 384 & 8723 & 7.3 & 19.3 & *13.3 & 19.8 \\
\hline Congo DR & 2014 & 536 & 16,994 & 18.9 & 17.0 & *15.3 & 17.4 \\
\hline Gabon & 2012 & 334 & 5414 & 6.2 & 16.8 & $* 11.2$ & 17.2 \\
\hline Northern Africa & & 874 & 15,458 & 17.7 & 14.0 & ${ }^{*} 16.4$ & 13.5 \\
\hline Egypt & 2014 & 874 & 15,458 & 17.7 & 14.0 & *16.4 & 13.5 \\
\hline Southern Africa & & 2544 & 25,529 & 5.3 & 15.5 & 16.9 & 15.4 \\
\hline Lesotho & 2014 & 396 & 2824 & 0.9 & 12.2 & 8.1 & 12.3 \\
\hline Namibia & 2013 & 536 & 4449 & 6.2 & 19.1 & *15.4 & 19.3 \\
\hline South Africa & 2016 & 668 & 3241 & 1.4 & 11.0 & 11.6 & 11.0 \\
\hline Zambia & 2018 & 545 & 9311 & 10.3 & 15.5 & 17.3 & 15.3 \\
\hline Zimbabwe & 2015 & 399 & 5704 & 1.2 & 17.1 & 23.6 & 17.0 \\
\hline West Africa & & 6285 & 139,382 & 61.6 & 14.7 & $* 15.2$ & 13.9 \\
\hline Benin & 2018 & 555 & 12,512 & 65.5 & 10.5 & 10.5 & 10.6 \\
\hline Burkina Faso & 2010 & 573 & 13,621 & 83.8 & 14.9 & $* 14.4$ & 17.2 \\
\hline Cote d'Ivoire & 2012 & 351 & 6876 & 64.0 & 18.5 & *16.6 & 21.7 \\
\hline Gambia & 2013 & 281 & 7633 & 59.4 & 17.8 & *16.4 & 19.7 \\
\hline Ghana & 2014 & 427 & 5539 & 27.4 & 11.9 & $* 14.4$ & 10.9 \\
\hline Guinea & 2015 & 401 & 7213 & 76.6 & 14.6 & 14.7 & 14.3 \\
\hline Liberia & 2013 & 322 & 6806 & 41.8 & 22.7 & 22.0 & 23.2 \\
\hline Mali & 2018 & 345 & 9171 & 73.0 & 17.2 & 17.6 & 16.4 \\
\hline Niger & 2012 & 476 & 11,437 & 85.7 & 14.4 & *14.0 & 16.4 \\
\hline Nigeria & 2018 & 1389 & 30,603 & 45.0 & 12.8 & *16.3 & 10.0 \\
\hline Senegal & 2017 & 400 & 11,253 & 61.4 & 18.0 & *18.7 & 17.0 \\
\hline Sierra Leone & 2013 & 435 & 10,254 & 69.4 & 11.5 & 11.5 & 11.5 \\
\hline Togo & 2013 & 330 & 6464 & 40.5 & 15.2 & $* 17.3$ & 13.8 \\
\hline Central Asia & & 682 & 10,216 & 1.7 & 10.2 & *18.6 & 10.0 \\
\hline Kyrgyz Rep & 2012 & 316 & 4222 & 0.0 & 5.2 & 0.0 & 5.2 \\
\hline
\end{tabular}


Table 1 description of demographic and health surveys data by countries, educational and diarrhoea prevalence among under-five children in LMIC, 2010-2018 (Continued)

\begin{tabular}{|c|c|c|c|c|c|c|c|}
\hline \multirow[t]{2}{*}{ Country } & \multirow{2}{*}{$\begin{array}{l}\text { Year } \\
\text { of } \\
\text { Survey }\end{array}$} & \multirow{2}{*}{$\begin{array}{l}\text { Number } \\
\text { of } \\
\text { Clusters }\end{array}$} & \multirow{2}{*}{$\begin{array}{l}\text { Number of } \\
\text { Under } 5 \text { Children }\end{array}$} & \multirow{2}{*}{$\begin{array}{l}\text { Weighted } \\
\text { (\%) } \\
\text { Illiterate }\end{array}$} & \multicolumn{3}{|c|}{ Weighted Diarrhoea Prevalence (\%) } \\
\hline & & & & & Overall & alliterate & ${ }^{\mathrm{b}}$ Literate \\
\hline Tajikistan & 2017 & 366 & 5994 & 2.7 & 13.3 & *18.7 & 13.1 \\
\hline South-Eastern Asia & & 1850 & 17,168 & 6.4 & 9.0 & $* 12.5$ & 8.7 \\
\hline Cambodia & 2014 & 609 & 6934 & 13.7 & 12.9 & 13.4 & 12.8 \\
\hline Philippines & 2017 & 1241 & 10,234 & 1.1 & 6.1 & 4.1 & 6.1 \\
\hline Southern Asia & & 33,053 & 322,219 & 33.3 & 11.5 & $* 14.5$ & 10.1 \\
\hline Afghanistan & 2015 & 956 & 30,520 & 83.2 & 29.1 & 29.0 & 29.9 \\
\hline Bangladesh & 2014 & 600 & 7541 & 16.4 & 5.7 & 5.9 & 5.7 \\
\hline India & 2016 & 28,321 & 247,181 & 29.5 & 9.2 & *9.5 & 9.1 \\
\hline Indonesia & 2017 & 1967 & 17,155 & 1.0 & 14.2 & 13.8 & 14.2 \\
\hline Maldives & 2016 & 265 & 3048 & 1.3 & 4.2 & 0.0 & 4.3 \\
\hline Nepal & 2016 & 383 & 4827 & 34.1 & 7.7 & 8.6 & 7.2 \\
\hline Pakistan & 2018 & 561 & 11,947 & 48.5 & 19.2 & $* 17.5$ & 20.8 \\
\hline Western Asia & & 2048 & 27,441 & 32.7 & 21.8 & *30.7 & 17.5 \\
\hline Armenia & 2016 & 306 & 1709 & 5.6 & 3.8 & 6.2 & 3.7 \\
\hline Jordan & 2017 & 962 & 10,454 & 1.6 & 9.7 & $* 4.6$ & 9.7 \\
\hline Yemen & 2013 & 780 & 15,278 & 55.1 & 31.4 & 31.5 & 31.3 \\
\hline Central America & & 1996 & 22,524 & 12.4 & 18.7 & 17.7 & 18.8 \\
\hline Guatemala & 2014 & 856 & 12,038 & 18.5 & 19.2 & ${ }^{*} 17.1$ & 19.7 \\
\hline Honduras & 2011 & 1140 & 10,486 & 4.8 & 18.0 & 20.4 & 17.9 \\
\hline South America & & 1401 & 9408 & 3.1 & 12.3 & 8.9 & 12.4 \\
\hline Peru & 2012 & 1401 & 9408 & 3.1 & 12.3 & 8.9 & 12.4 \\
\hline Southern Europe & & 651 & 2745 & 1.4 & 6.1 & 0.0 & 6.2 \\
\hline Albania & 2018 & 651 & 2745 & 1.4 & 6.1 & 0.0 & 6.2 \\
\hline Caribbean & & 1860 & 21,129 & 18.3 & 15.0 & $* 12.0$ & 15.7 \\
\hline Dominican Rep & 2013 & 516 & 3560 & 2.3 & 18.2 & 13.3 & 18.3 \\
\hline Haiti & 2016 & 449 & 6082 & 19.9 & 21.4 & 19.5 & 21.9 \\
\hline Myanmar & 2014 & 440 & 4575 & 17.8 & 10.5 & 10.7 & 10.4 \\
\hline Timor-Leste & 2016 & 455 & 6912 & 25.0 & 10.8 & $* 7.5$ & 11.9 \\
\hline Oceania & & 755 & 8415 & 25.5 & 15.4 & 15.0 & 15.6 \\
\hline Papua New Guinea & 2016 & 755 & 8415 & 25.5 & 15.4 & 15.0 & 15.6 \\
\hline
\end{tabular}

**significant at $5 \%$ chi-square test *significant at $5 \%$ test of equality of proportions between a and b

ent contribution of $X_{1}$ and $X_{2}$ to the group's gap is expressed as

$$
\frac{1}{N^{L}} X \sum_{i=1}^{N^{L}} F\left(\hat{\alpha}^{*}+X_{1 i}^{L} \hat{\beta}_{1}^{*}+X_{2 i}^{I} \hat{\beta}_{2}^{*}\right)-F\left(\hat{\alpha}^{*}+X_{1 i}^{L} \hat{\beta}_{1}^{*}+X_{2 i}^{I} \hat{\beta}_{2}^{*}\right)
$$

and

$$
\frac{1}{N^{L}} X \sum_{i=1}^{N^{L}} F\left(\hat{\alpha}^{*}+X_{1 i}^{L} \hat{\beta}_{1}^{*}+X_{2 i}^{I} \hat{\beta}_{2}^{*}\right)-F\left(\hat{\alpha}^{*}+X_{1 i}^{L} \hat{\beta}_{1}^{*}+X_{2 i}^{L} \hat{\beta}_{2}^{*}\right)
$$

respectively. The contribution of each variable to the gap is thus equal to the change in the average predicted probability from replacing the group $L$ distribution with the group $I$ distribution of that variable while holding the distributions of the other variable(s) constant. To obtain an accurate decomposition estimate, Fairlie et al. recommended the replication of the decomposition from a minimum of 1000 subsamples and finding the mean values of estimates from each separate decomposition [29]. Further numerical details have been reported [29, 31, 33, 34, 36].

We invoked the "Fairlie" Ado file in STATA 16 (StataCorp, College Station, Texas, United States of America) to carry out the decomposition analysis using the 
Table 2 Summary of pooled sample characteristics of the studied children and prevalence of diarrhoea in 57 LMIC

\begin{tabular}{|c|c|c|c|c|c|c|}
\hline \multirow[t]{2}{*}{ Characteristics } & \multirow[t]{2}{*}{$\mathbf{n}$} & \multirow{2}{*}{$\begin{array}{l}\text { Weighted } \\
\%\end{array}$} & \multirow{2}{*}{$\begin{array}{l}\text { Weighted \% } \\
\text { Illiterate }\end{array}$} & \multicolumn{3}{|c|}{ Weighted Diarrhoea Prevalence (\%) } \\
\hline & & & & Overall & Illiterate & Literate \\
\hline \multicolumn{7}{|l|}{ Age } \\
\hline Infant & 164,438 & 20.7 & 31.7 & *17.4 & *18.6 & *16.9 \\
\hline 12-59 months & 631,712 & 79.4 & 34.0 & 13.4 & 15.1 & 12.5 \\
\hline \multicolumn{7}{|l|}{ Sex } \\
\hline Female & 389,173 & 48.9 & 33.8 & *13.8 & *15.3 & $* 13.0$ \\
\hline Male & 406,977 & 51.1 & 33.3 & 14.6 & 16.2 & 13.9 \\
\hline \multicolumn{7}{|l|}{ Household Head } \\
\hline Male & 669,287 & 84.1 & 34.7 & $* 14.2$ & *16.0 & $* 13.2$ \\
\hline Female & 126,863 & 15.9 & 27.4 & 14.5 & 14.2 & 14.6 \\
\hline \multicolumn{7}{|l|}{ Maternal age } \\
\hline $15-24$ years & 234,550 & 29.5 & 25.2 & *16.4 & $* 17.2$ & $* 16.1$ \\
\hline $25-34$ years & 414,014 & 52.0 & 33.9 & 13.2 & 15.3 & 12.2 \\
\hline $35-49$ years & 147,586 & 18.5 & 46.6 & 13.4 & 15.4 & 11.7 \\
\hline \multicolumn{7}{|l|}{ Wealth Index } \\
\hline Poorest & 202,853 & 25.5 & 54.2 & $* 15.1$ & $* 15.1$ & $* 15.2$ \\
\hline Poorer & 178,258 & 22.4 & 39.5 & 14.8 & 15.5 & 14.3 \\
\hline Middle & 158,228 & 19.9 & 30.6 & 14.2 & 15.9 & 13.5 \\
\hline Richer & 139,713 & 17.6 & 22.7 & 13.9 & 16.9 & 13.0 \\
\hline Richest & 117,098 & 14.7 & 12.4 & 12.5 & 18.0 & 11.8 \\
\hline \multicolumn{7}{|l|}{ Employment } \\
\hline Employed & 526,983 & 66.2 & 32.2 & $* 13.3$ & $* 14.1$ & *12.9 \\
\hline Unemployed & 269,167 & 33.8 & 35.2 & 16.0 & 18.8 & 14.5 \\
\hline \multicolumn{7}{|l|}{ Media access } \\
\hline No & 316,993 & 39.9 & 56.1 & $* 15.2$ & *15.3 & $* 15.1$ \\
\hline Yes & 478,517 & 60.2 & 19.6 & 14.2 & 16.5 & 12.9 \\
\hline \multicolumn{7}{|l|}{ Drinking water sources } \\
\hline Unimproved sources & 175,663 & 22.8 & 48.7 & *16.9 & $* 17.9$ & $* 16.0$ \\
\hline Improved sources & 595,332 & 77.2 & 30.2 & 13.6 & 14.9 & 13.0 \\
\hline \multicolumn{7}{|l|}{ Toilet type } \\
\hline Unimproved sources & 388,386 & 50.4 & 48.7 & *15.4 & 15.7 & $* 15.1$ \\
\hline Improved source & 382,305 & 49.6 & 19.8 & 13.1 & 16.0 & 12.4 \\
\hline \multicolumn{7}{|l|}{ Marital status } \\
\hline Never married & 23,560 & 3.0 & 10.6 & *16.9 & 13.9 & $* 17.2$ \\
\hline Currently Married & 739,740 & 92.9 & 34.7 & 14.0 & 15.8 & 13.1 \\
\hline Formerly married & 32,850 & 4.1 & 23.8 & 17.1 & 16.0 & 17.4 \\
\hline \multicolumn{7}{|l|}{ Cooking Fuel } \\
\hline Unclean/Biomass & 581,710 & 77.0 & 42.2 & $* 14.9$ & $* 15.4$ & $* 14.5$ \\
\hline Clean Fuel & 173,921 & 23.0 & 11.8 & 12.4 & 19.7 & 11.4 \\
\hline \multicolumn{7}{|l|}{ Housing materials } \\
\hline Unimproved sources & 676,227 & 89.5 & 36.9 & *14.8 & *16.0 & $* 14.2$ \\
\hline Improved source & 79,157 & 10.5 & 15.8 & 10.0 & 12.0 & 9.6 \\
\hline \multicolumn{7}{|l|}{ Weight at birth } \\
\hline Average+ & 643,472 & 84.0 & 32.6 & *13.6 & $* 14.9$ & $* 13.0$ \\
\hline
\end{tabular}


Table 2 Summary of pooled sample characteristics of the studied children and prevalence of diarrhoea in 57 LMIC (Continued)

\begin{tabular}{|c|c|c|c|c|c|c|}
\hline \multirow[t]{2}{*}{ Characteristics } & \multirow[t]{2}{*}{$\mathbf{n}$} & \multirow{2}{*}{$\begin{array}{l}\text { Weighted } \\
\%\end{array}$} & \multirow{2}{*}{$\begin{array}{l}\text { Weighted \% } \\
\text { Illiterate }\end{array}$} & \multicolumn{3}{|c|}{ Weighted Diarrhoea Prevalence (\%) } \\
\hline & & & & Overall & Illiterate & Literate \\
\hline Small & 90,809 & 11.9 & 36.9 & 17.2 & 19.8 & 15.7 \\
\hline Very small & 31,924 & 4.2 & 44.7 & 20.1 & 21.1 & 19.3 \\
\hline \multicolumn{7}{|l|}{ Birth Interval } \\
\hline 1st Birth & 223,779 & 28.2 & 18.6 & *13.1 & *14.5 & *12.8 \\
\hline$<36$ months & 308,310 & 38.8 & 43.1 & 15.0 & 16.1 & 14.2 \\
\hline $36+$ months & 262,278 & 33.0 & 35.7 & 14.3 & 15.8 & 13.4 \\
\hline \multicolumn{7}{|l|}{ Birth Order } \\
\hline 1st & 223,777 & 28.1 & 18.6 & *13.1 & *14.5 & *12.8 \\
\hline 2nd & 192,088 & 24.1 & 24.7 & 13.1 & 14.3 & 12.7 \\
\hline $3 r d$ & 129,829 & 16.3 & 35.2 & 14.2 & 14.9 & 13.8 \\
\hline $4+$ & 250,456 & 31.5 & 50.4 & 16.2 & 17.0 & 15.2 \\
\hline \multicolumn{7}{|l|}{ Location } \\
\hline Urban & 239,222 & 30.1 & 17.7 & *13.4 & 15.9 & *12.9 \\
\hline Rural & 556,928 & 70.0 & 41.0 & 14.6 & 15.7 & 13.8 \\
\hline \multicolumn{7}{|c|}{ Neighbourhood SES } \\
\hline Highest & 159,709 & 20.1 & 9.2 & *9.8 & *11.9 & *9.6 \\
\hline 2 & 158,969 & 20.0 & 21.8 & 14.9 & 15.9 & 14.6 \\
\hline 3 & 160,077 & 20.1 & 38.5 & 15.8 & 16.7 & 15.2 \\
\hline 4 & 159,153 & 20.0 & 45.3 & 16.7 & 17.8 & 15.8 \\
\hline Lowest & 158,242 & 19.9 & 55.1 & 14.0 & 13.8 & 14.2 \\
\hline Total & 796,150 & 100.0 & 33.5 & 14.2 & 15.8 & 13.4 \\
\hline
\end{tabular}

*significant at $5 \%$ chi-square test

generalized structure of the model. We specified random ordering of the variables, sample weights and 10,000 replications of the decomposition to obtain optimal results that fully reflect the study population. Model fit was assessed using the Wald chi-square statistics and the log-likelihood ratio test. The $\mathrm{R}$ statistical software was used to draw all the Figures. All statistical tests were performed at 5\% significance level. The results of this study are presented in Tables and Figures. All our estimates were weighted.

\section{Results}

The LMIC included in this study are listed in Table 1 with their respective year of survey, the number of clusters, number of children, and percentage of children whose mothers are illiterate, the weighted prevalence of diarrhoea in all and specifically among children from illiterate and literate mothers. The overall proportion of children whose mothers were illiterate was $34 \%$, none in the Kyrgyz Republic, 1\% each in Lesotho and Indonesia and highest in Niger (86\%). The overall diarrhoea prevalence was $14.2 \%$ (significantly different across countries at $p<0.001)$, with 15.8 and $13.4 \%(p<0.001)$ among children from illiterate and literate mothers respectively (Table 1 and Fig. 1). The prevalence of diarrhoea among children whose mothers are illiterate ranged from $0.0 \%$ each in Albania and Maldives to $31.5 \%$ in Yemen while it ranged from $3.7 \%$ in Armenia to $31.3 \%$ in Yemen among children whose mothers are literate.

The z-test of equality of prevalence of diarrhoea among children from illiterate and literate mothers was statistically significant in 26 countries: Ethiopia $(p<0.001)$, Malawi $(p<0.001)$, Rwanda $(p<0.001)$, Tanzania $(p<0.001)$, Angola $(p<0.001)$, Cameroon $(p<0.001)$, Chad $(p<0.001)$, Congo $(p<0.001)$, Congo DR $(p<0.001)$, Gabon $(p<0.001)$, Egypt $(p<0.001)$, Namibia $(p<0.001)$, Burkina Faso $(p<0.001)$, Cote d'Ivoire $(p<0.001)$, Gambia $(p<0.001)$, Ghana $(p<0.001)$, Niger $(p<0.001)$, Nigeria $(p<0.001)$, Senegal $(p<0.001)$, Togo $(p<0.001)$, Tajikistan $(p<0.001)$, India $(p<0.001)$, Pakistan $(p<0.001)$, Jordan $(p<0.001)$, Guatemala $(p<0.001)$, and Timor-Leste $(p<0.001)$.

About $80 \%$ of the children were aged $12-59$ months, $52 \%$ of their mothers were aged $25-34$ years and $30 \%$ aged $15-24$ years while $70 \%$ are from rural areas (Table $2)$. We found statistical significance $(p<0.05)$ in the association between all the explanatory variable considered with the occurrence of diarrhoea among all the children 


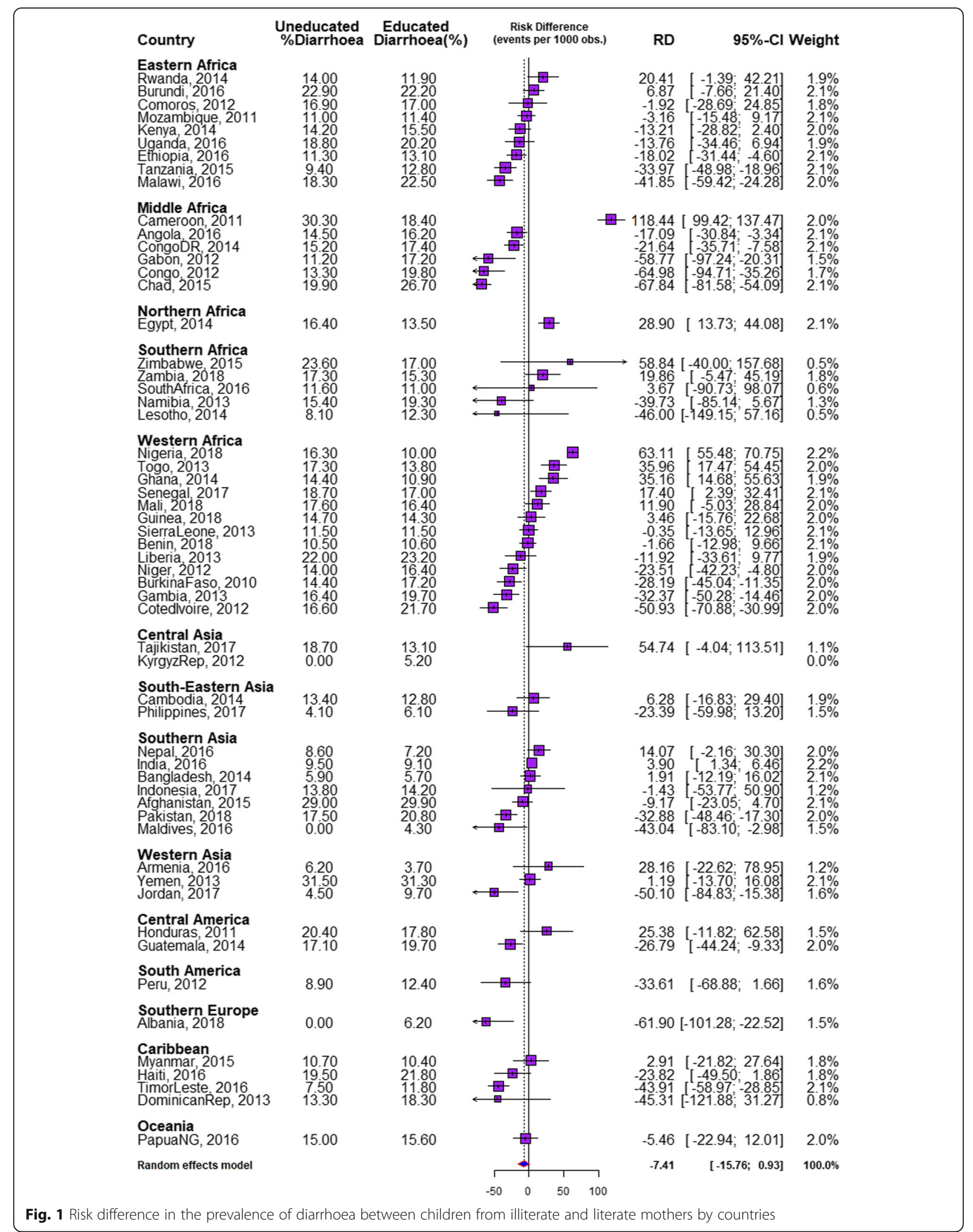




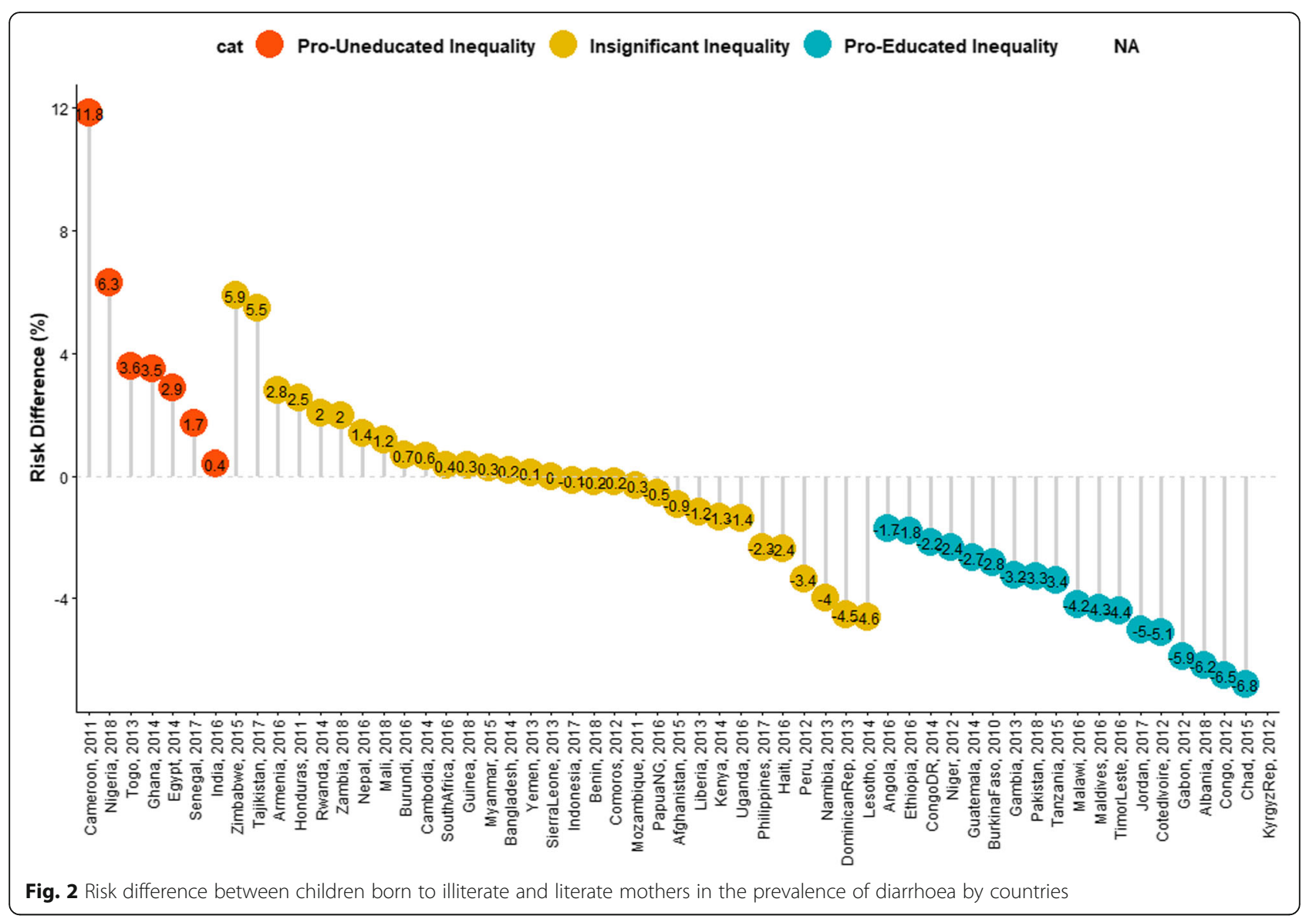

and also by the literacy status of the mothers except toilet types, marital status and place of residence that were not found to be significantly associated with the occurrence of diarrhoea among children whose mothers are illiterate. The prevalence of diarrhoea was consistently higher among the infants compared with those aged 1259 months irrespective of their mothers' educational status: $19 \%$ vs $15 \%$ among children whose mothers are illiterate and $17 \%$ vs $13 \%$ among children whose mothers are literate.

\section{Magnitude and variations in illiterate-literate inequality in diarrhoea}

The risk differences (RD) in having diarrhoea among children whose mothers are illiterate and those whose mothers are literate across the 57 countries as well as the meta-analysis of the RD are presented in Fig. 1. The RD was significantly higher among children whose mothers are illiterate than those from literate mothers in Cameroon, Nigeria, Togo, Ghana, Egypt, Senegal and India; higher among children whose mothers are literate in 18 countries (Angola, Congo, Congo DR, Ethiopia, Niger, Guatemala, Burkina Faso, Gambia, Pakistan, Tanzania, Malawi, Maldives,
Timor-Leste, Jordan, Cote d'Ivoire, Gabon, Albania, and Chad) and was insignificantly different in the 31 countries. The RD for the Kyrgyz Republic could not be computed (NA) because all mothers were literate in the country (Figs. 1, 2 and 3).

Irrespective of regions, the fixed effects of proilliterate RD in diarrhoea was widest in Cameroon (118.44/1000) while the fixed effects of pro-literate RD in diarrhoea was widest in Albania (-61.90/1000). The pro-illiterate $\mathrm{RD}$ in diarrhoea was significant only in some countries in Africa. In Middle Africa, the only pro-illiterate difference was in Cameroon and the largest pro-literate RD was in Chad (-67.84/ 1000). In Middle Africa, the only pro-illiterate difference was in Cameroon and the largest pro-literate RD was in Chad $(-67.84 / 1000)$. In Western Africa, the largest pro-illiterate difference was in Nigeria (63.11/ $1000)$ and the largest pro-literate RD was in Cote d'Ivoire $(-50.93 / 1000)$. The overall $\mathrm{RD}$, that's the random effects, per 1000 children were $-7.41 / 1000$ children (95\% confidence interval (CI): - 22.94-12.01), evidence of insignificant random effects and overall pro-literate inequality. The greatest contribution (weight) to the random effect was found in Nigeria 


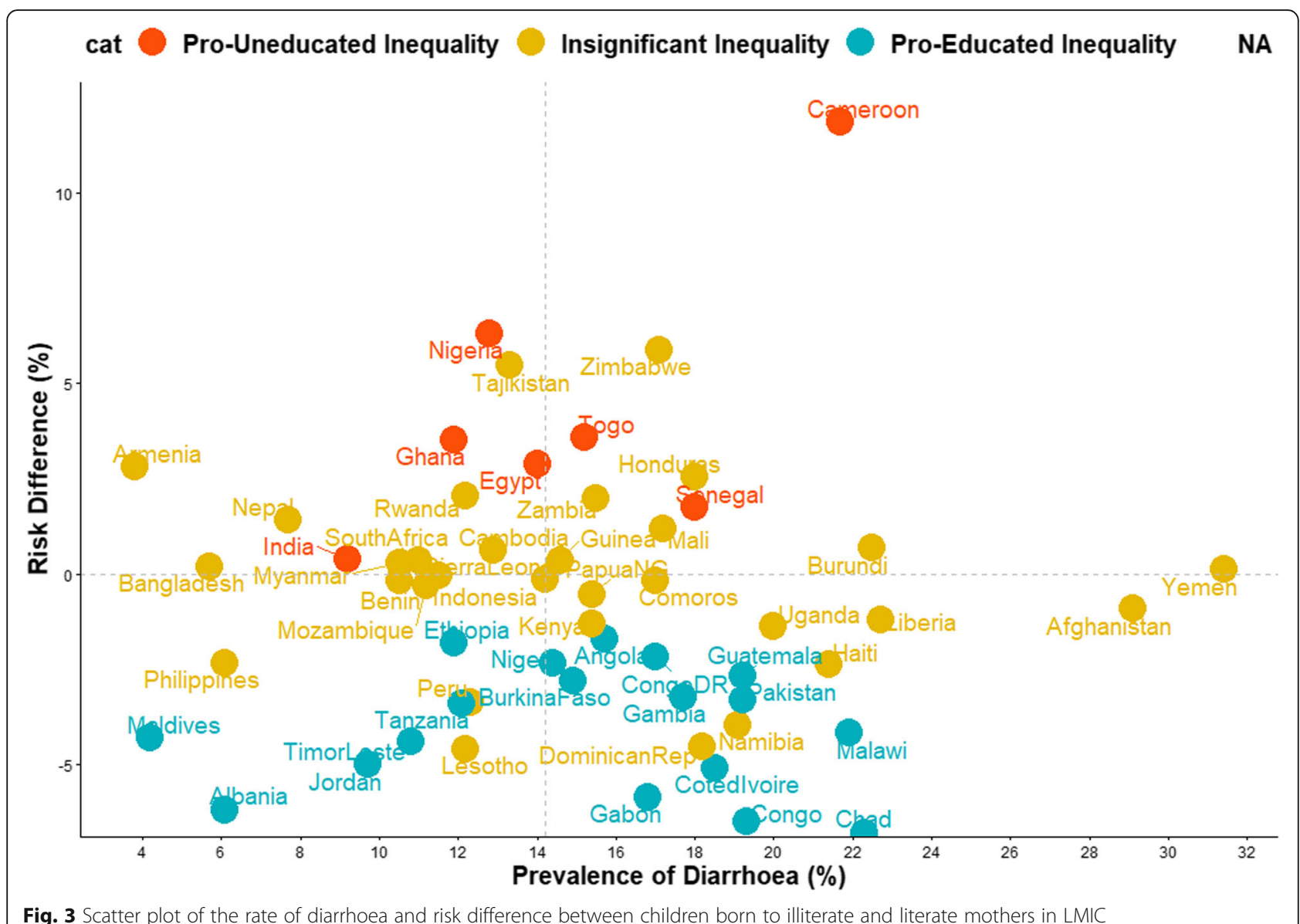

and India at $2.2 \%$ each while the least was in Zimbabwe and Lesotho at $0.5 \%$ each (Fig. 1). In Figs. 2 and 3, we used the colours red, orange and blue to indicate statistically significant pro-illiterate inequality, insignificant inequality and statistically significant proliterate inequality respectively.

\section{Relationship between prevalence of diarrhoea and magnitude of inequality}

The relationships between the prevalence of diarrhoea and the magnitude of educational inequality, a function of $\mathrm{RD}$, across the 57 countries are presented in Fig. 3. We categorized the countries into 4 distinct categories based on their prevalence of diarrhoea and whether or not the RD were small or large: (i) High diarrhoea prevalence and high pro-illiterate inequality countries such as Cameroon, Togo, and Senegal (ii) High diarrhoea prevalence and high pro-literate inequality countries such as Gabon, Congo and Chad (iii) Low diarrhoea prevalence and high pro-illiterate inequality countries such as Nigeria, Ghana and Egypt (iv) Low diarrhoea prevalence and high pro-literate inequality countries such as Maldives, Albania, and Jordan.

\section{Decomposition of educational inequality in the prevalence of diarrhoea}

We first computed Mantel-Haenszel pooled estimate of the odds ratio (OR) of having diarrhoea while controlling for country among all the children as 0.99 (95\% CI, 0.98-1.00) and tested the null hypothesis: $\mathrm{OR}=1$, we estimated $\mathrm{z}=1.09$ and $p=0.274$ and (ii) Test of heterogeneity $X^{2}=784.64$, degree of freedom (d.f.) $=56$, and $p=$ 0.000 , I-squared (variation in odds ratio (OR) attributable to heterogeneity) $=92.9 \%$.

The heterogeneity $\left(\mathrm{I}^{2}\right)$ was computed among countries from the same regions. In Eastern Africa, the $\mathrm{I}^{2}$ was 79 , 98\% in Middle Africa, 44\% in Southern Africa, 96\% in Western Africa. 84\% in Central America, 52\% in SouthEastern Asia, 81\% in Southern Asia, 78\% in Western Asia, $72 \%$ in the Caribbean. Only one country each were studied in the other regions, hence the $\mathrm{I}^{2}$ cannot be computed. Also, all mothers in the Kyrgyz Republic were educated, $\mathrm{I}^{2}$ was not computed for Central Asia as it had only Tajikistan.

Of the 57 countries, we found statistically significant pro-illiterate odds ratio in only 6 countries, 14 showed pro-literate inequality while other 37 countries had no statistically significant inequality. The 


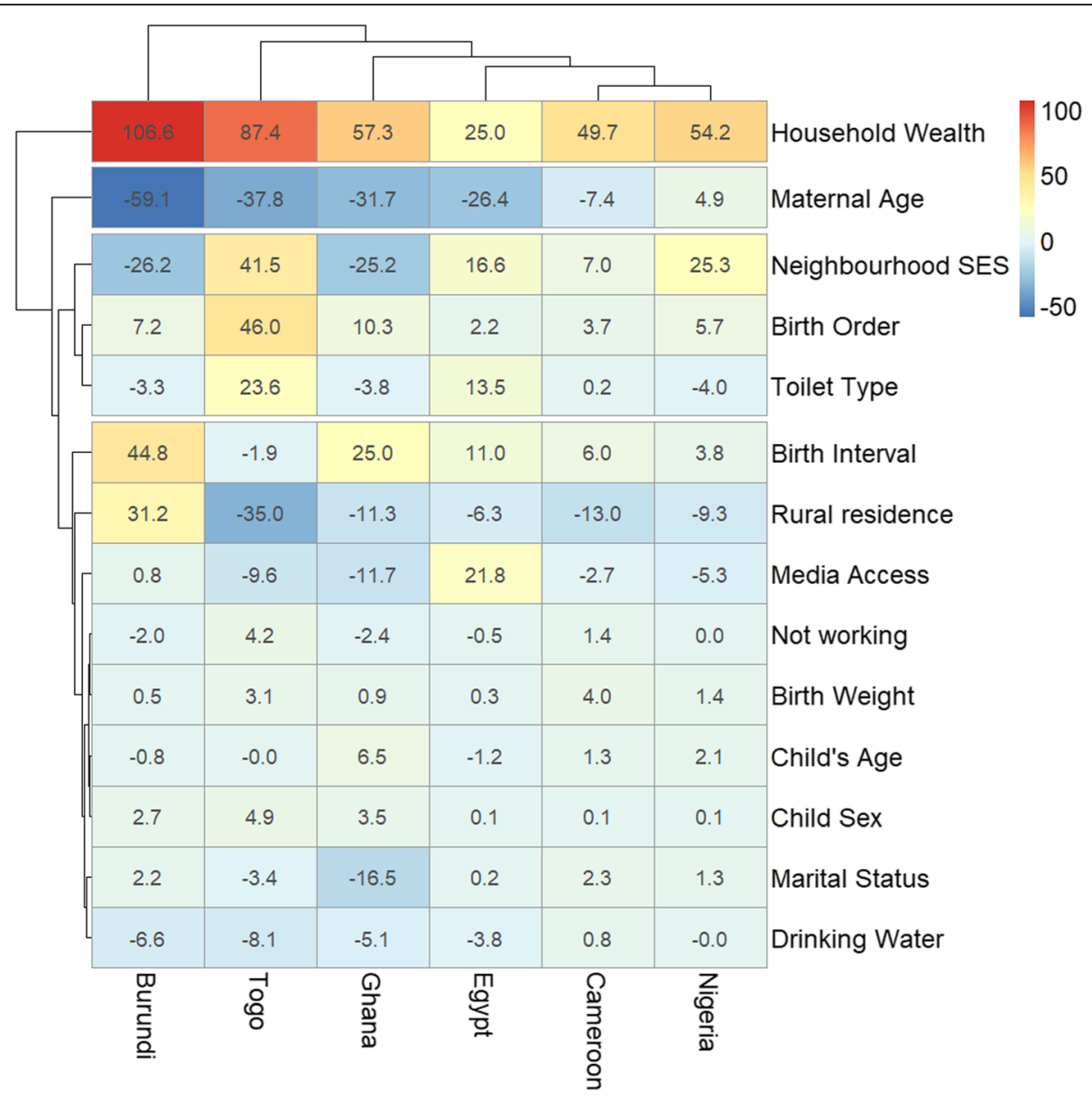

Fig. 4 Contributions of differences in the distribution 'compositional effect' of the determinants of diarrhoea to the total gap between children from illiterate and literate mothers by countries

countries with pro-illiterate inequalities are Burundi $(\mathrm{OR}=1.11 ; 95 \% \mathrm{CI}: 1.01-1.21 ; p=0.022)$, Cameroon $(\mathrm{OR}=1.84 ; 95 \%$ CI: $1.66-2.05 ; \mathrm{p}<0.001)$, Egypt $(\mathrm{OR}=$ 1.26; 95\% CI: $1.12-1.43 ; \mathrm{p}<0.001)$, Ghana $(\mathrm{OR}=1.24$; 95\% CI: $1.06-1.47 ; p=0.009)$, Nigeria $(\mathrm{OR}=1.80 ; 95 \%$ CI: $1.68-1.93 ; \mathrm{p}<0.001)$, and Togo $(\mathrm{OR}=1.21 ; 95 \%$ CI: $1.06-1.38 ; p=0.005)$. While significance was found in Burundi in the binary logistic estimates, such was not found in India and Senegal that had significant pro-illiterate RDs in Fig. 3.

We then computed Mantel-Haenszel pooled estimate of the odds ratio (OR) of having diarrhoea among the children in all these 6 countries while controlling for the countries. We estimated OR $=1.47$ (95\% CI: $1.41-1.52$ ) and tested the homogeneity of the ORs: $X^{2}=113.64$, d.f. $=6$, and $p=0.000$. All the tests were significant.

The Fairlie decomposition analysis was carried out on only the 6 LMIC with significant pro-illiterate inequalities. Figures 4 show the detailed Fairlie decomposition analysis of the part of the pro-illiterate caused by compositional effects of the risk factors associated with diarrhoea among U5C from the pro-illiterate countries. The "explained" (compositional component) and the "unexplained" (structural component) portions of the inequalities are shown in red and blue colours respectively in Fig. 4. The lighter the red colour, the lower the percentage contribution of the "explained" portion of the inequalities attributable to specified characteristics in the individual countries. On the other way, the lighter the blue colour, the lower the percentage contribution of the "unexplained" portion of the inequalities attributable to specified characteristics in the individual countries. We found wide variations in the factors associated with the pro-illiterate and pro-literate inequalities across the countries. The underlying logistic models used in the decomposition analysis for each of the countries fitted the data. The Wald chi-square statistics with corresponding degrees of freedom for each country were Burundi $\left(X^{2}(25)=114.10, p<0.001\right)$, Cameroon $\left(X^{2}(25)=158.61\right.$, $p<0.001)$, Egypt $\left(X^{2}(25)=265.85, p<0.001\right)$, Ghana $\left(X^{2}(25)=63.87, p<0.001\right)$, Nigeria $\left(X^{2}(25)=317.61, p<\right.$ $0.001)$ and Togo $\left(X^{2}(25)=83.73, \quad p<0.001\right)$. These 
statistics suggest that the coefficients were not simultaneously equal to zero. In addition, the log-likelihood ratio tests were significant.

Across the 6 countries, the largest contributions to gaps in having diarrhoea among the two groups of children are household wealth status, maternal age, neighbourhood SES, birth order, toilet type, birth interval and place of residence. Of these most important contributors, there was evidence of clustering among neighbourhood SES, birth order and toilet type, as well as between birth intervals and place of residence. These two clusters then clustered together at higher levels, first by the maternal age and then by the household wealth status (Fig. 4). Among the countries, the contributions of the risk factors to the pro-illiterate inequalities in having diarrhoea was highest in Burundi, then Togo, Ghana, Egypt, Cameroon and least in Nigeria as shown in Fig. 4.

As shown in Fig. 4, there are values greater than 100\%. This is because decomposition analysis works by separating the contributions of the factors into explained and unexplained which are arithmetically denoted as positives and negatives respectively. It is, therefore, possible to have both $>+100 \%$ and $>-100 \%$ as such will net out. Specifically, the largest contributions to pro-illiterate inequality in the prevalence of diarrhoea in Burundi were household wealth status (as it contributed 107\% of the difference in diarrhoea prevalence among groups of children from literate versus illiterate mothers), maternal age $(59 \%)$, birth intervals (45\%), and rural residence (31\%). Household wealth status (87\%), followed by birth order (46\%), neighbourhood SES (42\%), maternal age $(38 \%$,$) , and rural residence (31\%) were the greatest con-$ tributors to the inequalities in Togo. In Ghana, the main contributors to the educational inequalities were household wealth status $(57 \%)$, maternal age (32\%), neighbourhood SES (25\%), and birth intervals (25\%). Household wealth status, maternal age and media access were most significant in Egypt, household wealth status stood out in Cameroon while household wealth status and neighbourhood gave the highest explanation of the inequality in Nigeria. Other factors such as mothers' current employment status, birth weight, the age and sex of the child, as well as mothers' marital status and sources of drinking water had the lowest contribution to educational-related inequalities in the prevalence of diarrhoea across these countries. The clustering of the factors in the heat map refers to more closely related contributors to the inequalities.

\section{Discussion}

The study aimed to decompose the factors associated with educational inequalities in the development of diarrhoea among under-five children across 57 low- and middle-income countries. The study was conducted to gain a better understanding of the endowment or compositional differences and the coefficient or unexplained differences that are associated with educational inequalities in the development of diarrhoea in the different countries especially those countries with pro-illiterate inequalities. We found variability in maternal literacy levels across the countries with regards to diarrhoea among U5C, and this may be attributed to the country's existing nutrition strategies, policies, and interventions, as well as socio-economic status variations.

The adjusted random-effects showed that there are no significant differences in the development of diarrhoea among the children of the educated and the uneducated mothers generally irrespective of their countries of residence. Nonetheless, our analysis indicates an unequal balance between children of literate and illiterate mothers vis-a-vis the prevalence of diarrhoea within the countries. This is suggestive of maternal educational inequality being associated with the development of diarrhoea among children in LMIC. Of the 57 countries, children of illiterate mothers from 6 countries had significantly higher odds of diarrhoea, while diarrhoea prevalence was higher among children whose mothers were literate in 18 countries. Among the countries with statistically significant proilliterate inequalities, the risk difference of developing diarrhoea was widest in Cameroon (118 per 1000 children) and Nigeria (63 per 1000 children). The risk of diarrhoea has been previously correlated to maternal education, which can ultimately result in poorer health outcomes among children [37, 38]. This calls for an urgency of public health policies that are nutrition-specific, as well as programmes that can inform the design of tailored interventions that address the need to educate and train mothers to be able to make informed decisions about the nutrition of their children. Maternal education is also important as it influences household income and material resources within the household [37].

Maternal knowledge, practices and attitudes during childhood diarrhoea can be enhanced by education. According to Caldwell et al., child health can be improved solely by education enhancing the utilization of contemporary health services, or education may result in a host of complimentary behaviours that link to childcare and therefore contribute to the improvement of child health [39]. Besides, educational inequalities can make mothers unaware of a child's nutritional requirements during diarrhoea, as diarrhoea hampers micronutrient and calorie intake, and therefore preventing adequate nutritional support and a greater likeliness of mortality. Diarrhoeal diseases and bacterial infections may affect child nutrition, and therefore clean water and sanitation are vital to reduce these infections and diseases [13]. 
Therefore, mothers must be included in health promotion, which includes information campaigns, outreach programs that highlight health awareness and preservation, as well as focus on risks, as part of a comprehensive health framework focusing on child nutrition. This requires concerted efforts from the community and political leaders, as well as scientists and healthcare personnel [40]. Maternal education protects against infant diarrhoea in the more economically and socially advantaged communities but does not affect the more disadvantaged communities. Nonetheless, a major setback in women's educational inequalities especially in LMIC is that girls from poor families are most likely to remain out of school or have the strong likelihood to drop out even if they have a chance to start [41].

Closely related to the role of education in child health is media access to mothers as documented in an earlier study [42]. Research has shown that media is effective in the transmission of knowledge and information and therefore, should be included in national educational programs [43]. Efficient health education and media access over time can result in increased hygiene practice improvement, access and quality of water and sanitation, improved hygienic food preparation and access to nutritious food, as prevention measures for diarrhoea control in children [44],

We found wide variations in the factors associated with the pro-illiterate inequalities in the development of diarrhoea across the countries. The decomposition analysis indicates that of the 57 countries, only six countries, namely Burundi, Togo, Ghana, Egypt, Cameroon and Nigeria, had a statistically significant pro-illiterate odds ratio. To address and obtain a decreased cutback in maternal educational inequalities in diarrhoea, there has to be a greater understanding of the structural and contextual environment that the child lives. Previous studies identified the variations of country, community and individual stage factors associated with child health [44-46]. The greatest contributions to gaps in having diarrhoea among the two groups of children are household wealth status, maternal age, neighbourhood SES, birth order, toilet type, birth interval and place of residence across the six countries. The significance of these variables is consistent with previous studies, whereby diarrhoea was likely to occur in children whose mothers had little or formal education [47-51]. This is even though toilet types, marital status and place of residence were not found to be significantly associated with the occurrence of diarrhoea among children whose mothers are illiterate in the bivariate analysis. This finding could be attributed to different factors.

We found that children in rural areas are at a disadvantage of educational inequality in having diarrhoea than those living in urban areas. This is consistent with the literature. A study in Pakistan indicated that mothers in urban areas had better access to sanitation and healthcare facilities, improved water sources and also greater knowledge on the control and prevention of diarrhoea [52]. Literature indicates that essentially educated mothers have better understanding and knowledge regarding appropriate child feeding practices, hygiene, early diarrhoea signs and symptoms, which are major determinants for the occurrence of diarrhoea in children. It is also more likely that education impacts behaviour change at the household level and so awareness about methods of diarrhoea prevention and transmission may be greater $[8,13]$.

Our findings on household wealth, as the greatest factor associated with educational inequalities in the development of diarrhoea, are consistent with the literature $[12,53]$. These studies indicate that there are higher risks of diarrhoea diseases in poorer households, while a child from a well-off household is likely better access to healthcare services, and therefore have better health outcomes. Income inequality is a major driver of educational inequalities among girls and women [54]. UNICEF and UNESCO were unanimous that the world's lowincome countries remain home to poverty and large income inequalities which invariably lead their girls to marry early without reasonable education $[18,55]$.

The mapping of the relationship between educational inequality and diarrhoea prevalence conducted in this study revealed that there are different categories of country viz-a-viz their level of diarrhoea prevalence and educational inequality. The mapping helped to identify the countries that need to urgently revisit, develop and re-strategize diarrhoea prevention strategies with a focus on the prevailing level of educational inequality in different countries. We found that countries such as Cameroon, Togo, and Senegal had a high prevalence of diarrhoea and high pro-illiterate inequality, while countries such as Jordan, Maldives and Albania had a low prevalence of diarrhoea and high pro-educated inequality. These disparities can be attributed to household wealth status, neighbourhood SES, current child nutrition policies and programmes at the country-level, as well as economic and political stability in different countries.

There are definite learning curves from countries with a low prevalence of diarrhoea and low pro-educated inequalities for countries with high diarrhoea prevalence and high pro-illiteracy inequalities. This can include realignment of or new nutrition policies and programmes for child health. Also, there is clear evidence of significant pro-educated inequality in some countries, this may be suggestive of the mother not having sufficient health education. That is, despite education, mothers' knowledge, attitude and practice of diarrhoea prevention may 
be poor or insufficient. Further research to fully understand the structural and compositional factors that drive pro-literate inequalities in the development of diarrhoea is a pointer that diarrhoea prevention strategies should not be limited to only the uneducated mothers.

There are possibilities of path dependence between educational attainment and some of the risk factors. For instance, women with better education are more likely to belong to households in the richest wealth quintiles and vice versa [56]. On the other way round, people from poor households have a low likelihood of better education or even any education in some cases. Thus some contributors to the gap, are both causes and consequences of the inequalities.

It is striking that the risk of diarrhoea was higher among the children of educated women than among the children of uneducated mothers in countries such as Albania, Jordan, Gabon, Congo, Chad etc. This might have been affected by the type of food consumed. There is a possibility of "food poison" through "fast foods" which are more common among educated women than among uneducated women $[57,58]$. Health education and promotion on how mothers could avoid or at least minimise the incidence of diarrhoea in those countries are necessary.

Although the level of education does not seem to be associated with under-5 diarrhoea in 37 countries in this study, as the gaps were insignificantly different, this does not necessarily translate to a lower risk of diarrhoea in those countries. The finding is an indication that the educational level of mothers does not significantly influence the risk of diarrhoea among children in those countries. In particular, countries such as Comoros, Uganda, Liberia, Haiti, Afghanistan and Yemen have a worrisome prevalence of diarrhoea. Stakeholders in these countries and others should focus on reducing the incidence of diarrhoea and also enhance adequate management of diarrhoea cases.

\section{Conclusion}

The study identified inequalities in the prevalence of diarrhoea in children with variations in mothers' literacy levels. Education-related inequalities in diarrhoea prevalence were identified and were explained by different risk factors at the individual, household and community levels. In explaining the inequalities in the prevalence of diarrhoea, our main determinant variable in this study, mothers' literacy, highlights the importance of education to all countries, especially the girl child, as they are potential future mothers and their educational status may influence their health and that of their children. Maternal education is a vital factor that provides information and also enhances the autonomy level of a woman who can empower herself to provide good care of her child
[59]. Education has the power to provide knowledge, change one's attitude, practices and behaviours so that good health can be attained [59]. This can result in reducing the prevalence and morbidity and mortality associated with diarrhoea. In countries with pro-uneducated inequalities, urgent interventions are important to address the public health issue of diarrhoea as the second leading cause of death in children under five years.

\section{Recommendations for public health action}

While enhancing the education of women, due attention must be given to enhancing individuals' capacity for better livelihood, reduced fertility, childbirth at younger ages, improved toilet types, sufficient birth intervals, and rural residence. The study findings are important and concerted efforts must be made to design public health programmes and policy on childhood diarrhoea disease. There should also be collaborative efforts between governments and key stakeholders to focus on communities with a high level of illiteracy and should include programmes and interventions on access to healthcare, basic amenities such as water and sanitation, as well as hygiene practice techniques to address diarrhoea risk factors. Universal access to school for all women is vital so that the identified gap in diarrhoea among children with uneducated and educated mothers is lessened.

\section{Strength and limitation}

A major limitation of our study is that the outcome variable is based on mothers' ability to accurately recall the occurrence of diarrhoea among their under-five children without any means of verification. Correct identification of what diarrhoea is could be a potential bias. However, the provision of an exclusive description of how diarrhoea should be identified to the data collectors by the DHS could have limited the effect of this bias. Also, the data collectors were given a similar regimen of training across the countries, this would have improved both intra- and inter-country comparison. The very low levels of illiteracy among mothers in some countries could have reduced the precision of our estimates in those countries. Besides, our study has a strength of wide coverage of LMIC (57) using the DHS data that is comparable across countries. We quantified the magnitude of the explained and unexplained factors associated with educational-inequalities in the development of diarrhoea. Besides, we have used the Fairlie decomposition techniques which is more appropriate for binary outcomes although it is not necessarily an alternative measure of causality. However, it provided robust evidence of educational-related inequalities after controlling for the exposure variables. 


\section{Abbreviations}

BODA: Blinder-Oaxaca Decomposition Analysis; Cl: Confidence Interval; DHS: Demographic and Health Survey; FDA: Fairlie Decomposition Analysis; IRB: Institutional Review Board; LMIC: Low- And Middle-Income Countries; PSU: Primary Sample Unit; RD: Risk Difference; SES: Socioeconomic Status; U5C: Under-Five Children; UNICEF: United Nations International Children's Emergency Fund; WHO: World Health Organization

\section{Acknowledgements}

The authors are grateful to ICF Macro, USA, for granting the authors the request to use the DHS data. We appreciate the logistic supports provided by the consortium for advanced research and training in Africa (CARTA) to AFF in the course of writing this paper.

\section{Authors' contributions}

AFF conceptualised, designed the study, curated and analysed the data. All authors (AFF, KA, ND, OSF and OAU) contributed to literature search, figures, data interpretation, writing of the manuscript. All authors have read and approved the manuscript.

\section{Funding}

The authors received no funding for this study.

\section{Availability of data and materials}

The data supporting this article is available at http://dhsprogram.com.

\section{Declarations}

\section{Ethics approval and consent to participate}

This study was based on the analysis of openly available secondary data. The Institutional Review Board (IRB) of ICF Macro at Fairfax, Virginia in the USA reviewed and approved the MEASURE Demographic and Health Surveys Project Phase III. The 2010-2018 DHS's are categorized under that approval. The IRB of ICF Macro complied with the United States Department of Health and Human Services requirements for the "Protection of Human Subjects" (45 CFR 46). Written informed consent was obtained from every study participant before participation and all information was collected without identifiers and kept confidentially. In addition, written informed consent was obtained from a parent or guardian for participants under 16 years old. ICF Macro permitted the authors to use the data. The full details of the ethical approvals can be found at http://dhsprogram.com.

\section{Consent for publication}

Not applicable.

\section{Competing interests}

The authors declare that they have no competing interests.

\section{Author details}

'Department of Epidemiology and Medical Statistics, Faculty of Public Health, College of Medicine, University of Ibadan, Ibadan, Nigeria. ${ }^{2}$ Warwick Centre for Global Health, Division of Health Sciences, University of Warwick, Coventry, UK. ${ }^{3}$ General Studies Unit, School of Sciences, Federal University of Technology, Akure, Nigeria. ${ }^{4}$ Human and Social Capabilities Division, Human Sciences Research Council, Cape Town, South Africa. ${ }^{5}$ Techmodia, West Sussex, UK. ${ }^{6}$ Portsmouth Business School, Faculty of Business and Law, University of Portsmouth, Portsmouth, UK. ${ }^{7}$ Division of Epidemiology and Biostatistics, Department of Global Health, Faculty of Health Sciences, Stellenbosch University, Francie van Zijl Drive, Tygerberg, 7505 Cape Town, South Africa

Received: 14 July 2020 Accepted: 15 June 2021

Published online: 24 June 2021

\section{References}

1. UNICEF/WHO. Diarrhoea: why children are still dying and what can be done. Geneva: UNICEF and WHO; 2009.

2. WHO. Preventing diarrhoea through better water, sanitation and hygiene. Geneva: 2014. http://apps.who.int/iris/bitstream/handle/10665/150112/ 9789241564823 eng.pdfijsessionid=69D5ADFD275A2F0070A8EC2 E9F0B75BF?sequence=1. Accessed 30 Mar 2021.
3. UNICEF. One is too many: ending child deaths from pneumonia and diarrhoea. New York; 2016. Available from: https://www.unicef.org/publica tions/index_93020.html. Accessed 3 Aug 2020.

4. UNICEF. The state of the World's children 2016: a fair chance for every child. New York: UNICEF; 2016. Available from: https://www.unicef.org/publica tions/index_91711.html. Accessed 3 Aug 2020.

5. Mokomane M, Kasvosve I, de Melo E, Pernica JM, Goldfarb DM. The global problem of childhood diarrhoeal diseases: emerging strategies in prevention and management. Ther Adv Infect Dis. SAGE Publications; 2018 [cited 2019 Aug 7];5:29-43. Available from: http://www.ncbi.nlm.nih.gov/ pubmed/29344358. Accessed 3 Aug 2020.

6. UN Inter-agency Group for Child Mortality Estimation. Levels and Trends in Child Mortality. New York: 2018. https://www.un.org/en/development/desa/ population/publications/mortality/child-mortality-report-2018.asp. Accessed 30 Mar 2021.

7. Adebola OG. Disparirities in access to improved and unimproved sources of drinking water and toilet facilites in Nigeria: a socio-economic dichotomy. J Sustain Technol. 2019;10:104-11.

8. Melese B, Paulos W, Astawesegn FH, Gelgelu TB. Prevalence of diarrheal diseases and associated factors among under-five children in Dale District, Sidama zone, southern Ethiopia: a cross-sectional study. BMC Public Health. 2019;19:1-10.

9. Agegnehu MD, Bewket Zeleke L, Goshu YA, Ortibo YL, Mehretie Adinew Y. Diarrhea Prevention Practice and Associated Factors among Caregivers of Under-Five Children in Enemay District, Northwest Ethiopia. J Environ Public Health. Hindawi; 2019 [cited 2019 Aug 20]:1-8. Available from: https:/www. hindawi.com/journals/jeph/2019/5490716/. Accessed 3 Aug 2020.

10. Van Malderen C, Amouzou A, Barros AJD, Masquelier B, Van Oyen H, Speybroeck N. Socioeconomic factors contributing to under-five mortality in sub-Saharan Africa: a decomposition analysis. BMC Public Health. 2019;19(1): 760. https://doi.org/10.1186/s12889-019-7111-8.

11. Ahs JW, Tao W, Löfgren J, Forsberg BC. Diarrhoeal Diseases in Low- and MiddleIncome Countries: Incidence, Prevention and Management. Open Infect Dis J. 2010 [cited 2019 Aug 20]:4:113-24. Available from: https://pdfs.semanticscholar. org/0096/6b7bb3a3a78dd597e987a81cc8cb6a12b518.pdf. Accessed 3 Aug 2020.

12. Budhathoki SS, Bhattachan M, Yadav AK, Upadhyaya P, Pokharel PK. Eco-social and behavioural determinants of diarrhoea in under-five children of Nepal: a framework analysis of the existing literature. Tropical Med Int Health. 2016;44:1-5.

13. Alebel A, Tesema C, Temesgen B, Gebrie A, Petrucka P, Kibret GD. Prevalence and determinants of diarrhea among under-five children in Ethiopia: A systematic review and meta-analysis. Pietroni M, editor. PLoS One. Public Library of Science; 2018 [cited 2019 Aug 7];13:e0199684. Available from:. https://doi.org/10.1371/journal.pone.0199684.

14. Workie HM, Sharifabdilahi AS, Addis EM. Mothers' knowledge, attitude and practice towards the prevention and home-based management of diarrheal disease among under-five children in Diredawa, Eastern Ethiopia, 2016: a cross-sectional study. BMC Pediatr. BioMed Central; 2018 [cited 2019 Aug 20];18:358. Available from: http://www.ncbi.nlm.nih.gov/pubmed/30453926. Accessed 3 Aug 2020.

15. Bohra T, Benmarhnia T, Mckinnon B, Kaufman JS. Decomposing educational inequalities in child mortality : a temporal trend analysis of access to water and sanitation in Peru. Am J Trop Med Hyg. 2017;96(1):57-64. https://doi. org/10.4269/ajtmh.15-0745.

16. Woldu W, Bitew BD, Gizaw Z. Socioeconomic factors associated with diarrheal diseases among under-five children of the nomadic population in northeast Ethiopia. Trop Med Health. BioMed Central; 2016 [cited 2019 Aug 24]:44:40. Available from: http://tropmedhealth.biomedcentral.com/articles/1 0.1186/s41182-016-0040-7. Accessed 3 Aug 2020.

17. Habtu M, Nsabimana J, Mureithi C. Factors Contributing to Diarrheal Diseases among Children Less than Five Years in Nyarugenge District, Rwanda. J Trop Dis. 2017;5:238. https://doi.org/10.4172/2329-891X.1000238.

18. UNICEF. The investment case for education and equity [internet]. New York; 2015. Available from: https://www.unicef.org/publications/files/Investment_ Case_for_Education_and_Equity_FINAL.pdf. Accessed 3 Aug 2020.

19. ICF International. Demographic and health survey: sampling and household listing manual [internet]. Calverton; 2012. Available from: https://www. dhsprogram.com/pubs/pdf/DHSM4/DHS6_Sampling_Manual_Sept2012_ DHSM4.pdf. Accessed 3 Aug 2020.

20. Croft TN, Marshall AMJ, Allen CK. Guide to DHS statistics [internet]. 2018. Available from: https://dhsprogram.com/pubs/pdf/DHSG1/Guide_to_DHS_ Statistics_DHS-7.pdf. Accessed 3 Aug 2020. 
21. Fufa KW, Gebremedhin GB, Gebregergs GB, Mokonnon MT. Assessment of Poor Home Management Practice of Diarrhea and Associated Factors among Caregivers of Under-Five Years Children in Urban and Rural Residents of Doba Woreda, Ethiopia: Comparative Cross-Sectional Study. Int J Pediatr. Hindawi; 2019 [cited 2019 Aug 7];2019:1-12. Available from: https:// www.hindawi.com/journals/ijpedi/2019/8345245/. Accessed 3 Aug 2020.

22. Nilima KA, Shetty K, Unnikrishnan B, Kaushik S, Rai SN. Prevalence, patterns, and predictors of diarrhea: A spatialoral comprehensive evaluation in India 11 Medical and Health Sciences 1117 Public Health and Health Services. BMC Public Health. BioMed Central Ltd.; 2018 [cited 2020 Apr 12];18:1288. Available from: https://bmcpublichealth.biomedcentral.com/articles/10.1186/ s12889-018-6213-z. Accessed 3 Aug 2020.

23. National Population Commission(NPC)[Nigeria], ICF International. Nigeria Demographic and Health Survey 2018. Abuja, Nigeria, and Rockville, Maryland, USA: 2019. https://dhsprogram.com/publications/publication-fr3 59-dhs-final-reports.cfm. Accessed 30 Mar 2021.

24. Roser M, Ortiz-Ospina E. Global Rise of Education [Internet]. Ourworldindata. org. 2019 [cited 2019 Jun 29]. p. 1. Available from: https://ourworldindata. org/global-rise-of-education. Accessed 3 Aug 2020.

25. Powers DA, Yoshioka H, Yun M. mvdcmp: Multivariate decomposition for nonlinear response models. Stata J. 2011;11(4):556-76. https://doi.org/10.11 77/1536867X1201100404

26. Oaxaca R. Male-female wage differentials in urban labor markets. Int Econ Rev. 1973;14(3):693-709. https://doi.org/10.2307/2525981.

27. Hlavac M. oaxaca: Blinder-Oaxaca Decomposition in R [Internet]. R Packag. version 0.1.4. 2018. p. 1. Available from: https://cran.r-project.org/package= oaxaca. Accessed 3 Aug 2020.

28. Blinder AS. Wage discrimination: reduced form and structural estimates. J Hum Resour. 1973;8(4):436-55. https://doi.org/10.2307/144855.

29. Fairlie RW. Addressing Path Dependence and Incorporating Sample Weights in the Nonlinear Blinder-Oaxaca Decomposition Technique for Logit, Probit and Other Nonlinear Models. Stanford; 2017. Report No.: 17-013.

30. Fairlie RW, Robb AM. Why Are Black-Owned Businesses Less Successful than White-Owned Businesses? The Role of Families, Inheritances, and Business Human Capital. J Labor Econ. 2007;25:289-323.

31. Fairlie RW. An Extension of the Blinder-Oaxaca Decomposition Technique to Logit and Probit Models [Internet]. Yale; 2003. Report No.: 873. Available from: http://ssrn.com/abstract=497302. Accessed 3 Aug 2020.

32. Fairlie RW. An extension of the Blinder-Oaxaca decomposition technique to logit and probit models. J Econ Soc Meas. 2005;30(4):305-16. https://doi. org/10.3233/JEM-2005-0259.

33. Jann B. Fairlie: Stata module to generate nonlinear decomposition of binary outcome differentials [Internet]. 2006 [cited 2020 Apr 6]. p. 1. Available from: http://ideas.repec.org/c/boc/bocode/s456727.html. Accessed 3 Aug 2020.

34. Fairlie RW. The absence of the African-American owned business: an analysis of the dynamics of self-employment. J Labor Econ. 1999;17(1):80108. https://doi.org/10.1086/209914.

35. Jann B. A Stata implementation of the Blinder-Oaxaca. Stata J. 2008;8(4): 453-79. https://doi.org/10.1177/1536867X0800800401.

36. Norman G, Pedley S, Takkouche B. Effects of sewerage on diarrhoea and enteric infections: a systematic review and meta-analysis. Lancet Infect Dis. 2010 [cited 2019 Aug 20];10:536-44. Available from: https://linkinghub. elsevier.com/retrieve/pii/S1473309910701237. Accessed 3 Aug 2020.

37. Mawa R, Lawoko S. Malnutrition among children under five years in Uganda. Am J Heal Res. 2018;6(2):56-66. https://doi.org/10.11648/j.ajhr.20180602.14.

38. Mbugua S, Musikoyo E, Ndungi F, Sang R, Kamau-Mbuthia E, Ngotho D. Determinants of diarrhea among young children under the age of five in Kenya, evidence from KDHS 2008-09. Afr Popul Stud. 2014;28(0):1046-56. https://doi.org/10.11564/28-0-556

39. Caldwell J. Education as a factor in mortality decline an examination of Nigerian data. Popul Stud. 1979;33(3):395-413. https://doi.org/10.2307/2173888.

40. Corcia C, Mastroiacovo P. Health promotion for children, mothers and families: here's why we should "think about it before conception". Ital J Pediatr. 2013;39:1-4.

41. OXFAM. The power of education to fight inequality. 2019. https://www.oxfa m.org/en/research/power-education-fight-inequality. Accessed 30 Jan 2021.

42. Dhingra D, Dabas A, Anand T, Pinnamaneni R. Maternal knowledge, attitude and practices during childhood diarrhoea. Trop Dr. 2018;48(4):298-300. https://doi.org/10.1177/0049475518787425.

43. Ghasemi AA, Talebian A, Alavi NM, Mousavi GA. Knowledge of Mothers in Management of Diarrhea in Under-Five Children, in Kashan, Iran. Nurs
Midwifery Stud. 2013 [cited 2019 Aug 20];1:158-62. Available from: http:// www.nmsjournal.com/?page=article\&article_id=10393. Accessed 3 Aug 2020.

44. Li R, Lai Y, Feng C, Dev R, Wang Y, Hao Y. Diarrhea in under Five Year-Old Children in Nepal: a Spatiotemporal Analysis Based on Demographic and Health Survey Data. Int J Environ Res Public Health. 2020;17(6):2140. https:// doi.org/10.3390/ijerph17062140.

45. Desmennu AT, Oluwasanu MM, John-Akinola YO, Oladunni O, Adebowale SA. Maternal education and diarrhea among children aged 0-24 months in Nigeria. Afr J Reprod Health. 2017;21(3):27-36. https://doi.org/10.29063/ajrh2 017/v21i3.2.

46. Fagbamigbe AF, Kandala NB, Uthman OA. Decomposing the educational inequalities in the factors associated with severe acute malnutrition among under-five children in low- and middle-income countries. BMC public health. BMC Public Health. 2020;20:1-14. Available from:. https://doi.org/1 0.1186/s12889-020-08635-3.

47. Boadi $\mathrm{KO}$, Kuitunen M. Childhood diarrheal morbidity in the Accra Metropolitan Area, Ghana: Socio-economic, environmental and behavioral risk determinants. J Health Popul Dev Ctries. 2005; Available from: http:// www.jhpdc.unc.edu/. Accessed 3 Aug 2020.

48. Mohammed S, Tamiru D. The burden of diarrheal diseases among children under five years of age in Arba Minch district, southern Ethiopia, and associated risk factors: a cross-sectional study. Int Sch Res Notices. 2014; 2014:654-901.

49. Sinmegn Mihrete T, Asres Alemie G, Shimeka Teferra A. Determinants of childhood diarrhea among underfive children in Benishangul Gumuz Regional State, North West Ethiopia. BMC Pediatr. 2014;14:102. https://doi. org/10.1186/1471-2431-14-102.

50. Yilgwan CS, Okolo S. Prevalence of diarrhea disease and risk factors in Jos University teaching hospital, Nigeria. Ann Afr Med. 2012;11:212. Available from:. https://doi.org/10.4103/1596-3519.102852.

51. Teklemichael G, Mohammed T, Wondwosen K. Assessment of the risk factor of diarrheal disease in under-five children among the health extension model and non-model family in Sheko district rural community, Southwest Ethiopia 2014;14:395. BMC Public Health. 2014;14:2-6.

52. Arif A, Arif G. Socio-economic determinants of child health in Pakistan. Acad Res Int. 2012;2(1):398-42.

53. Mahumud RA, Alam K, Renzaho AMN, Sarker AR, Sultana M, Sheikh N, et al. Changes in inequality of childhood morbidity in Bangladesh 1993-2014: a decomposition analysis. PLoS One. 2019;14:e0218515. Available from: https://doi.org/10.1371/journal.pone.0218515.

54. Oppedisano V, Turati G. What are the causes of educational inequality and of its evolution over time in Europe? Evidence from PISA. Education Economics. 2015;23(1):3-24. https://EconPapers.repec.org/RePEc:taf:edecon: v:23:y:2015:i:1:p:3-24.

55. UNESCO. UNESCO and gender equality in sub-Saharan Africa: innovative programmes, visible results [internet]. France; 2017. Available from: https:// unesdoc.unesco.org/ark:/48223/pf0000259590. Accessed 3 Aug 2020.

56. Fagbamigbe AF, Bamgboye EA, Yusuf BO, Akinyemi JO, Issa BK, Ngige E, et al. The Nigeria wealth distribution and health seeking behaviour : evidence from the 2012 national HIV / AIDS and reproductive health survey. Heal Econ Rev. 2015;5:e1-10.

57. UNICEF. The State of the World's Children 2019. Children, Food and Nutrition: Growing well in a changing world [Internet]. New York: UNICEF; 2019 [cited 2020 Nov 8]. Available from: https://www.unicef.org/media/ 60806/file/SOWC-2019.pdf. Accessed 3 Aug 2020.

58. Shau J-P, Chen P-H, Chan C-F, Hsu Y-C, Wu T-C, James FE, et al. Fast foodsare they a risk factor for functional gastrointestinal disorders? Asia Pac J Clin Nutr. 2016 [cited 2020 Nov 8];25:393-401. Available from: http://nahsit.nhri. org.tw/. Accessed 3 Aug 2020.

59. Bado AR, Susuman AS, Nebie El. Trends and risk factors for childhood diarrhea in sub-Saharan countries (1990-2013): assessing the neighborhood inequalities. Glob Health Action. Taylor \& Francis; 2016 [cited 2019 Aug 20]; 9:30166. Available from: http://www.ncbi.nlm.nih.gov/pubmed/27174860. Accessed 3 Aug 2020.

\section{Publisher's Note}

Springer Nature remains neutral with regard to jurisdictional claims in published maps and institutional affiliations. 